University of Nebraska - Lincoln

DigitalCommons@University of Nebraska - Lincoln

Architectural Engineering -- Faculty Publications

Architectural Engineering and Construction,

Durham School of

2011

Optimization of Energy Storage Systems in HEV's

Mahmoud Alahmad

University of Nebraska - Lincoln, malahmad2@unl.edu

Mohamed Amer Chaaban

University of Nebraska-Lincoln, mchaaban@unomaha.edu

Follow this and additional works at: https://digitalcommons.unl.edu/archengfacpub

Part of the Architectural Engineering Commons

Alahmad, Mahmoud and Chaaban, Mohamed Amer, "Optimization of Energy Storage Systems in HEV's" (2011). Architectural Engineering -- Faculty Publications. 51.

https://digitalcommons.unl.edu/archengfacpub/51

This Article is brought to you for free and open access by the Architectural Engineering and Construction, Durham School of at DigitalCommons@University of Nebraska - Lincoln. It has been accepted for inclusion in Architectural Engineering -- Faculty Publications by an authorized administrator of DigitalCommons@University of Nebraska Lincoln. 


\title{
Optimization of Energy Storage Systems in HEV's
}

\author{
Mahmoud. Alahmad, Muhammad F. Zulfiqar \\ malahmad2@unl.edu,mchaaban@unomaha.edu \\ University of Nebraska-Lincoln
}

\begin{abstract}
This paper introduces a novel battery model inspired by molecular structures mainly for applications in HEV's. This novel 3-D adaptive battery topology shows potential for improvement in input and output performance as well as the charging/ discharging efficiency of batteries. The proposed topology provides flexible connections between battery cells to achieve different configurations of battery. A new switching matrix has been developed to achieve the required configurations. Preliminary simulations provide promising results for an adaptive 3-D battery configuration. Comparison between traditional battery configurations and the adaptive 3-D configuration is considered. A significant improvement in power curves is achieved by the proposed topology.
\end{abstract}

Index Terms - Reconfigurable batteries, smart batteries, Switching Matrix, Hybrid Electric Vehicles, Cell Balancing.

\section{INTRODUCTION}

HYBRID ELECTRIC VEHICLE (HEV) is an optimal combination of two power sources, a conventional internal combustion engine (ICE) and a rechargeable energy storage system (battery) [1]. Increasing fuel costs and emission standards across the globe have popularized this alternative form of transportation. According to a recent survey [2], 36\% of motorists worldwide wish to buy a car with hybrid drive, while $46 \%$ of them showed interest in buying full-electric cars. Figure 1 shows the hybrid sales trend in the U.S. for all of 2007 with the initial sales in $2008(\sim 22,000)$ shown as one data point. Hybrid Electric Vehicles of all varieties are becoming pervasive and growing quickly [3].

However compared with lead-acid batteries and nickelmetal hydride (Ni-MH) batteries, Li-ion batteries are superior in terms of specific energy (the amount of available energy per unit of mass or volume) and in terms of specific power (the amount of available output per unit of mass or volume). As a result, they are seen as the most promising batteries for secondary-battery applications. A summary of battery characteristics for EV and HEV applications is given in [4].

Present commercial HEVs use a variety of energy operating strategies. For example, batteries may be used as the sole energy source at low speeds, or they may act as supplemental source during heavy acceleration. In-addition, they also provide an energy sink during regenerative braking [5]. The key point is that all these uses rely on the battery pack to support fast, high power transients. These power demands frequently result in a short-term state of (SoC) cycling of the battery pack, and require relatively high power densities in the cells. Most HEV manufacturers employ sophisticated control algorithms to manage these SoC swings within vehicles $[6,7]$, with the objective of delivering many thousands of charge and discharge cycles. It is well known that secondary batteries, in general, exhibit limits on cycle count.

Typically only a few hundred cycles can be delivered if the $0-100 \%$ SoC range is employed. Most of the strategies employed for long cycle life are based on rigorous prequalification: extremely careful matching and characterization, and careful quality control of battery cells. Cells are matched for impedance, voltage characteristics, and thermal properties. For this reason Li-ion cells require careful balancing, since it is not possible to use overcharge methods for cell equalization.

If the power stored by each battery cell is different, then there will be an even bigger difference in the terminal voltage displayed by each cell. Most charging circuits are only able to detect the terminal voltage of the entire battery module, using this to determine when to stop charging the batteries. For this reason, when the battery stops charging it is possible that some cells within the module have already reached an overcharged state, while other cells are still not fully charged [8-10]. Unbalanced ageing is less of a problem with parallel chains of cells, which tend to be self-balancing since the parallel connection holds all the cells at the same voltage and at the same time allows charge to move between cells whether or not an external voltage is applied. There can however be problems with this cell configuration if a short circuit occurs in one of the cells since the rest of the parallel cells will discharge through the failed cell exacerbating the problem.

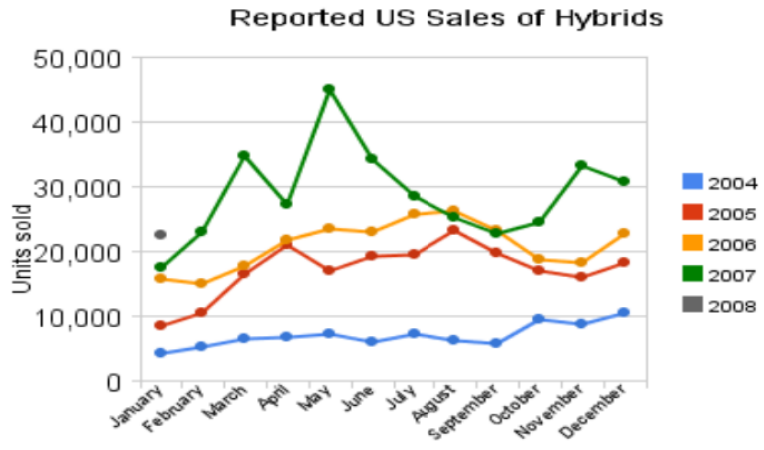

Fig. 1: HEV Sales in U.S. for 2007

Several methods have been proposed to solve the problems incurred in the fix-configuration battery design. A commonly used method to solve the problem of cell state variations is using a cell balancing circuit. However, most existing balancing circuits use dissipative resistors, resulting in energy loss [11]. The latest products of cell balancing integrated 
circuits (ICs) [12] use electronic converters to transfer charge from cell to cell during operation, leading to improved energy efficiency. However, this solution increases the cost and volume of the battery system. Moreover, most of these cell balancing ICs were developed for small multi-cell batteries in portable electronic devices. No such circuits are available for large-scale battery systems as yet. A more promising solution to the problems of the fix-configuration battery design is to develop reconfigurable batteries where each cell can be controlled and operated in different modes independently.

This paper proposes a new 3-D reconfigurable, multi-cell battery design. A new cell switching circuit topology is proposed where each cell can be controlled independently and only uses few switches to fully control its charge, discharge, and cutoff. The resulting battery system can be operated with variable terminal voltages to improve the energy conversion efficiency [11]. The cell switching circuit and the control circuit for each cell are designed and implemented by using high-efficiency power MOSFETs and small-signal electronic devices.

The proposed design can maximally utilize the battery's capacity, thereby maximizing the operating time and lifespan of the battery system. Moreover, the proposed design is tolerant to failures of single or multiple cells, thereby enhancing the reliability of the battery system. By using the proposed design, many additional monitoring, control, protection, and optimization functions can be added to each cell and the overall battery system to produce a smart battery.

This paper will cover, in section II, existing reconfigurable system configurations, in section III, the proposed topology, in section IV simulation model of the reconfigurable topology systems, and the conclusion in section $\mathrm{V}$.

\section{II.EXISTING RECONFIGURABLE SYSTEM CONFIGURATIONS}

In-order to minimize the in-efficiencies and maximize the performance of the battery in HEV applications, a reconfigurable battery topology was proposed in [12]. The reconfigurable battery system described in [12] is composed of a controller that manages a set of control units, and an array of battery cells. Each cell is equipped with a set of switches that each control unit is responsible for turning on or off, so that the cells can be connected online in series, in parallel, or both as shown in Fig. 2.

This topology allows up to N-battery cells to be connected in any desired configuration. This flexibility allows the topology, using a microprocessor based controller, to provide maximum voltage by connecting all batteries in series; provide maximum capacity by connecting the batteries in parallel; provide a voltage/capacity ratio by connecting the batteries in a parallel-series configuration. The topology also provides monitoring and status information and fault detection capabilities.

Most of existing charging and discharging systems cannot perform balancing in real-time, they just measure the voltage of battery cells and balance all of them using average voltage of the cells. This method is stable but has low performance because battery cells discharge until their voltages reach the average value which does not allow us to use the full power of battery.
Also, the proposed design is tolerant to failures of single or multiple cells, it does not allow the flexibility of different mismatched cells to be paired with similar cells in the pack. Thereby compromising enhanced battery life and the reliability of the battery system.

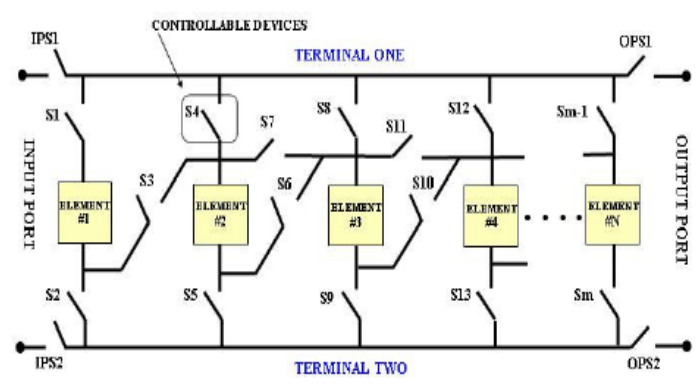

Fig. 2: Reconfigurable Battery topology

\section{THE PROPOSED TOPOLOGY}

This section details the benefits of a reconfigurable battery system, provides a physical insight into rechargeable battery cells, and then describes the motivation behind our work.

The reconfigurable battery topology proposed in this paper is shown in Fig. 3. It is an improvement of the topology we developed earlier in [11]. The new topology allows up to Nbatteries to be connected in any desired configuration in 3-D; providing maximum voltage, maximum capacity and a voltage/capacity ratio. This battery switch array system is part of a power management system that is developed to utilize these features and provide for multiple charging algorithms, real time status information and fault tolerant capabilities.

The reconfigurable topology allows us three types of capabilities. First, the coordination of terminals' connectivity and the terminal switches allows the cells to be charged and discharged simultaneously. That is, we can virtually partition the cells into two groups for charge and discharge activities, respectively. Second, an appropriate combination of onswitches allows for parallel-connected groups of the cells. These groups can then selectively be discharged at a time. Third, a single battery pack can be treated as one module, like a single cell, by connecting all the cells in the battery pack in series. These battery packs can then be connected in series, in parallel, or both. For simplicity, a cell is regarded as a module on which charge and discharge activities are scheduled. Based on these three types of capability, we build a framework of scheduling the charge, discharge, and rest activities for battery cells.

According to [11], battery charging is the most substantial issue in battery management systems. Basically, a charger has the following three functions: 1) delivering charge to the battery; 2) optimizing the charge rate; and 3) terminating the charge. We investigate the effects when charge is delivered to the reconfigurable battery through different charging schemes such as constant current constant voltage (CCCV), trickle charging and pulse charging.

The proposed battery topology has the following advantages over other reconfigurable topologies: 
- The proposed topology allows for more configurations for every cell in the battery pack.

- The new topology offers higher charge/ discharge efficiency as the cells being over charged can divert the incoming charge to less undercharged cells in the pack.

- The over-all battery life is enhanced by efficient charging and discharging resulting from perfectly matched cells being combined together to form strings.

- The new topology provides increased fault tolerance, as faulty cells can be isolated by controlling the connecting switches.

- The proposed battery topology provides enhanced reliability and safety from overheating cells.

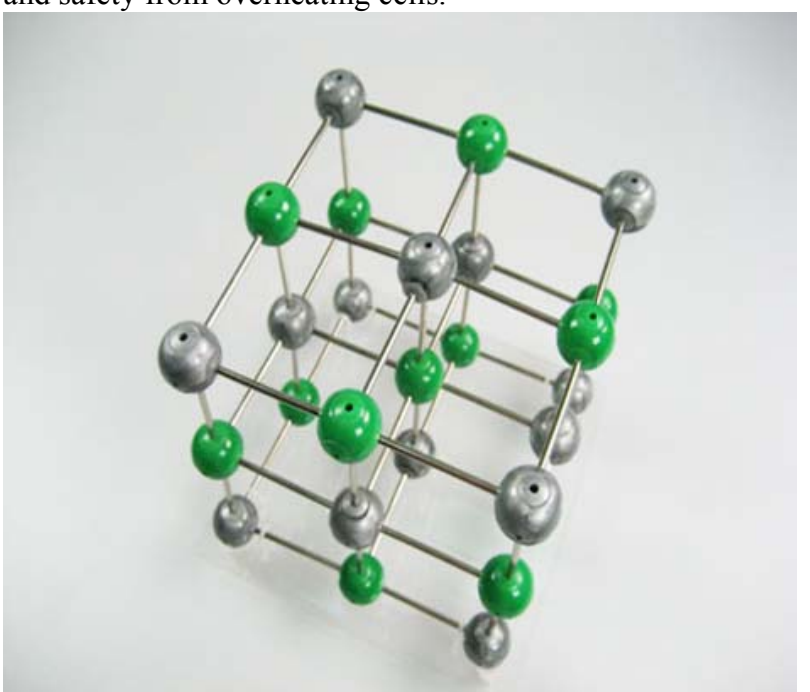

Fig. 3. Proposed reconfigurable battery inspired similar to Sodium chloride molecular structure.

The proposed architecture of the matrix that adaptively reconfigures the connections between battery cells consists of a number of controllable switches and a number of buses. As shown in Fig.3. In this Figure, the entire battery pack is included in the matrix, which consists of $\mathrm{N}$ number of cells. The arranging order of cells is based on the operating conditions.

The matrix architecture consists of switches and buses. The most important advantage of this matrix is the fact that it can connect battery cells, existing physically in different strings, in series. The cells arranging order in the matrix identifies the strings arranging order in the physical pack.

The switches are categorized according to their function. Switches are used to achieve the series connection between battery cells, i.e. connect the first cell with the second module in series. The series connection may be between non adjacent cells; for example, between the first and the third cells. This allows for a flexibility that is not provided in reconfigurable topologies found in literature. In addition these switches allow cells to be removed from the configuration. In the last example, the connection between the first and third cell is achieved bypassing the second module.

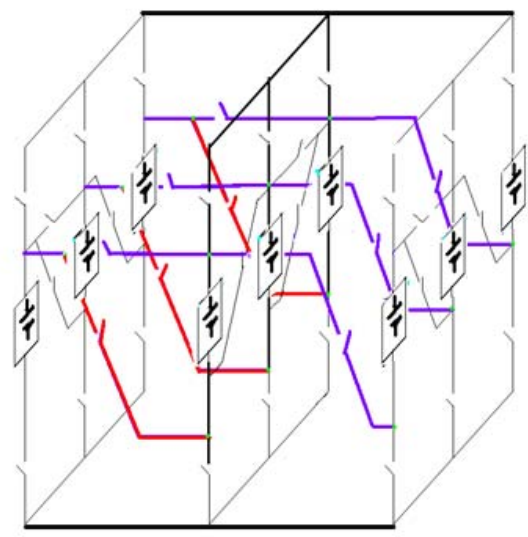

Fig. 4: The Proposed Switching Matrix

Activating any of the switches will establish the end of the string. e.g. to connect the third cell which is the end of the first string to the bus which allows this connection to be completed. Closing any of the switches will determine the beginning of the string.

For a $\mathrm{N}$-cell battery pack, $\mathrm{M}=5 * \mathrm{~N}$ switches are required. There are two buses used to connect strings of the pack. These buses are considered the point of common connection of the battery power in the circuit in order to supply the load.

The number of switches in the pack depends on the number of cells in the battery pack. Each cell requires five switches in order to achieve the adaptive system. Each bus requires two switches to connect the string.

\section{THE SIMULATION MODEL}

An accurate battery cell model is needed in order to validate the proposed design by simulation studies. Moreover, monitoring, control, protection, and optimization of battery systems to produce so called smart batteries also need an accurate battery cell model for SOC tracking, etc.

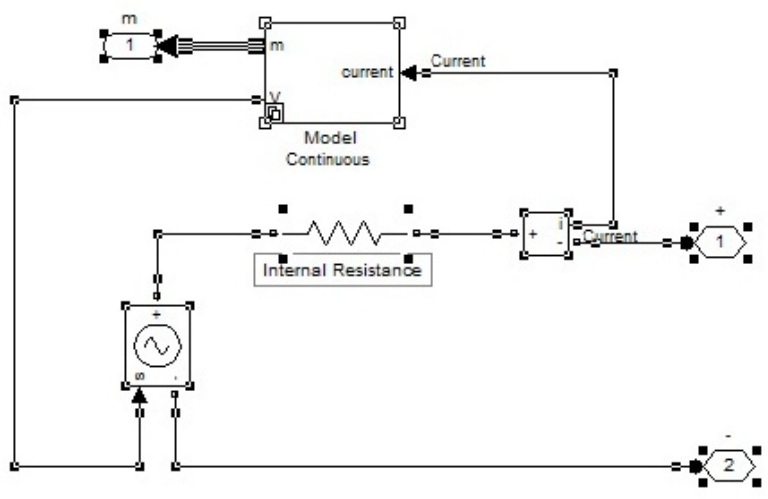

Fig. 5. Li-ion cell model used in simulating various topologies

This model can accurately predict battery cell runtime and $\mathrm{I}-\mathrm{V}$ performance while taking into account the effects of temperature and capacity fading on the cell dynamics. 
Using the simulation model shown in Fig. 5 and given in Simulink, the adaptive PV system is implemented where the number of cells in the pack can be changed by the user. The model offers preliminary comparison results between Adaptive \& Fixed battery configurations.

It is noticed that in normal operation condition, the simulation curves of fixed and adaptive systems are somewhat identical because of the similarity of the cells' configuration for both systems.

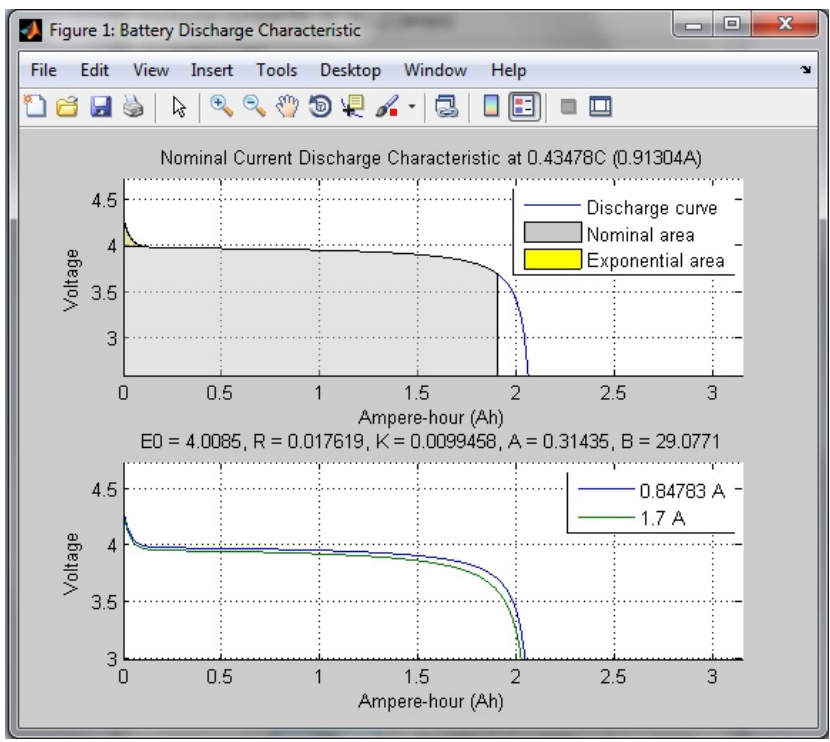

Fig. 6: Simulation Results of single Battery cell Discharge Characteristics

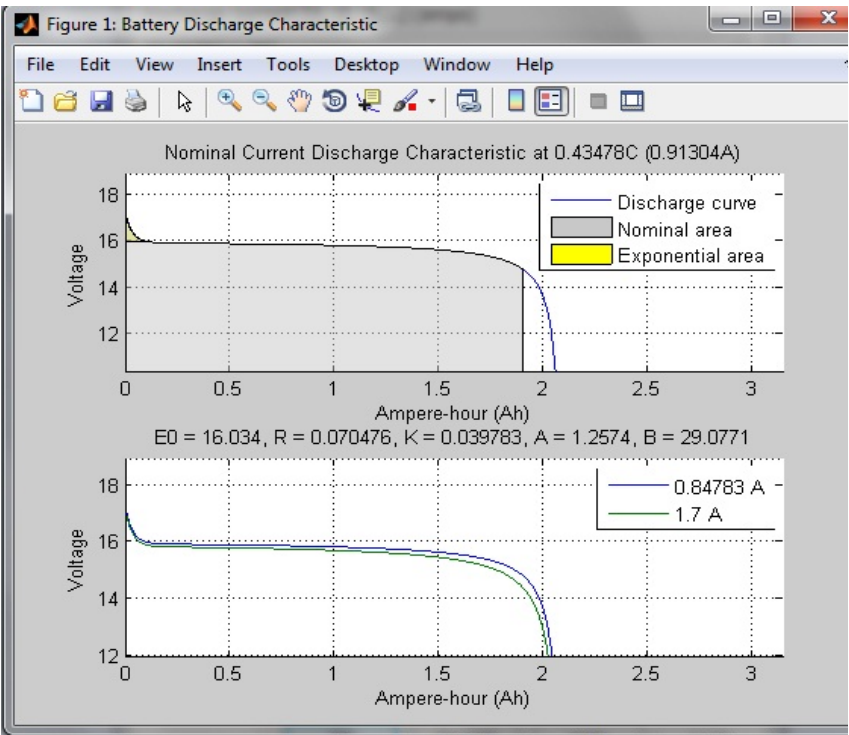

Fig. 6: Simulation Results of Discharge Characteristics of Battery cells in series

The reconfigurable topology can be configured to provide programmable voltage output as shown in Fig. 6. Using the 4.25 V, 2.1 Ah battery cells, the available voltages are multiples of $4.25 \mathrm{~V}, 8.5 \mathrm{~V}, 12.75 \mathrm{~V}$ and $17 \mathrm{~V}$ for a 4 cell battery. The capacity for each of the selectable voltages is 2.1 Ah.
The 3-D topology can also be configured to provide programmable capacity output. The available capacity is multiples of $2.1 \mathrm{Ah}$. The voltage at each of the selectable capacities is $4.25 \mathrm{~V}$. Such a topology with 4 cells connected in parallel is simulated and shown in Figure 7.

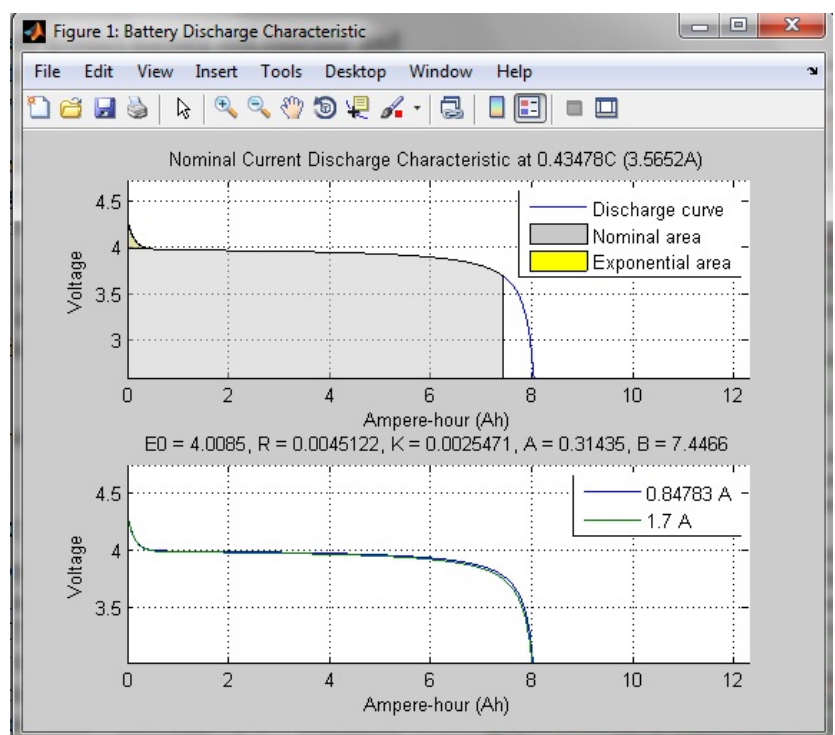

Fig. 7: Simulation Results of Discharge Characteristics of Battery cells in parallel

\section{CONCLUSION}

This paper has presented a novel 3-D, reconfigurable multi cell battery design based on molecular structure. A new switching circuit topology has been proposed where each cell in the battery only uses few switches to fully control its operation independently. The switching circuit and the control circuit for each cell have been designed and implemented by using high efficiency semiconductor devices. The proposed design can maximally utilize the battery's capacity and is tolerant to failures of single or multiple cells, thereby maximizing the lifespan and enhancing the reliability of the battery by allowing cells of different values to be paired with similar cells. By using the proposed design, additional monitoring, control, protection, and optimization functions can be readily added to each cell and the overall battery system, leading to a smart battery.

\section{REFERENCES}

[1] J. F. Fuller, E. F. Fuchs, and K. J. Roe Southampton: Wit Press, pp. 1-27, 2002

[2] Green Car Congress. International study shows global gains in consideration of hybrid and electric vehicles. http://www.greencarcongress.com/2008/06/international-s.html.

[3] John M. Miller, Trends in Vehicle Energy Storage Systems: Batteries and Ultracapacitors to Unite. IEEE Vehicle Power and Propulsion Conference (VPPC), September 3-5, 2008, Harbin, China.

[4] Burke, A.F.; , "Batteries and Ultracapacitors for Electric, Hybrid, and Fuel Cell Vehicles," Proceedings of the IEEE, vol.95, no.4, pp.806-820, April 2007 doi: 10.1109/JPROC.2007.892490

[5] Miller, J.M.; , "Energy storage system technology challenges facing strong hybrid, plug-in and battery electric vehicles," Vehicle Power and Propulsion Conference, 2009. VPPC '09. IEEE , vol., no., pp.4-10, 7-10 Sept. 2009. doi: 10.1109/VPPC.2009.5289879

[6] Kim, N.; Cha, S.; Peng, H.; , "Optimal Control of Hybrid Electric Vehicles Based on Pontryagin's Minimum Principle," Control Systems Technology, 
IEEE Transactions on , vol.PP, no.99, pp.1-9, 0 doi: 10.1109/TCST.2010.2061232

[7] Shah, V.A.; Karndhar, S.G.; Maheshwari, R.; Kundu, P.; Desai, H.; , "An energy management system for a battery ultracapacitor Hybrid Electric Vehicle," Industrial and Information Systems (ICIIS), 2009 International Conference on , vol., no., pp.408-413, 28-31 Dec. 2009 doi: 10.1109/ICIINFS.2009.5429825

[8] M.J. Isaacson, R.P. Hollandsworth, P.J. Giampaoli, F.A. Linkowsky, A. Salim, and V.L. Teofilo, "Advanced Lithium Ion Battery Charger," The Fifteenth Annual Battery Conference on Applications and Advances, pp. 193$198,2000$.

[9] M. Maskey, M. Parten, D. Vines, and T. Maxwell, "An Intelligent Battery Management System for Electric and Hybrid Electric Vehicles," IEEE Vehicular Technology Conference, vol. 2, pp. 1389-1391, 16-20 May 1999.

[10] J. Chatzakis, K. Falaitzakis, N.C. Voulgaris, and S.N. Manias "Designing a New Generalized Battery Management System," IEEE Transactions on Industrial Electronics, vol. 50, no. 5, October 2003, pp. 990-999.

[11] Al-Haj Hussein, A.; Batarseh, I.; , "A Review of Charging Algorithms for Nickel and Lithium Battery Chargers," Vehicular Technology, IEEE Transactions on , vol.60, no.3, pp.830-838, March 2011 doi: 10.1109/TVT.2011.2106527. 